\title{
ROLE OF CYCLODEXTRINS IN NEW ANTIMYCOBACTERIAL FORMULATIONS
}

\author{
Veaceslav Boldescu*, Fliur Macaev, Gheorghe Duca \\ Institute of Chemistry of Academy of Science of Moldova, 3, Academiei str., Chisinau MD2028, Republic of Moldova \\ *veaceslav.boldescu@gmail.com; phone: (+373 22) 73 97 58; fax: (+373 22) 739954
}

\begin{abstract}
This paper is dedicated to the role of cyclodextrins in new formulations for the treatment of infections with Mycobacterium tuberculosis that are in the process of design and development. Cyclodextrins play the role of solubilizing agents and promoters of the antimycobacterial substances penetration inside the mycobacterial cell. Different formulations and their advantages and disadvantages are discussed.
\end{abstract}

Keywords: cyclodextrin, nano-encapsulation, tuberculosis, mycobecteria, cholesterol.

\section{Introduction}

Tuberculosis is one of the deadliest infectious diseases killing annually 1.5 million people worldwide. The major problems connected with the tuberculosis treatment are: strong side effects of the majority of the existent antituberculosis drugs, long duration of treatment, high dosage, unpleasant organoleptic properties and high frequency of administration. These factors very often cause the lack of compliance of the patient with treatment. The last fact in association with low bioavailability and insufficient enantiomeric purity of some antituberculosis drugs, all together, lead to development of drug-resistant (DRTB), multiple drug-resistant (MDRTB), and extensively drug-resistant (XTRB) tuberculosis.

The problem with tuberculosis puts the Republic of Moldova among the top five European countries with high rate of new infections. The current situation becomes more complicated because of high percentage (approx. 25\%) of MDRTB infections, with proportion of previously treated cases that became MDRTB reaching 65.1\% [1].

In order to resolve the problem a multidisciplinary approach is needed. One of the possibilities can be introduction of more patient-friendly types of antituberculosis drugs with lower frequency of administrations, shorter time of treatment, lower doses and fewer side effects. For the development of such drugs a wide knowledge in phthisiology and tuberculosis drugs chemistry is needed.

For improvement of the efficiency of new antituberculosis formulations and reduction of their side effects and time of treatment, new formulations with cyclodextrins have been proposed. Different formulations and their advantages and disadvantages are further discussed.

\section{Different approaches to improve the efficiency of antituberculosis drugs}

In order to reduce duration of treatment, frequency and quantity of the administered doses of drugs, to avoid first pass effect and to reduce the side effects, new antituberculosis drug entities and different micro- and nanoparticle based systems for nebulisation have been proposed.

Thus, in the field of the micro- and nanoparticulate systems, a lyposomal system loaded with rifampicin is known. The system contains phosphatidile choline and cholesterol as main vehicles. In order to increase the specificity of the system accumulation in macrophages, it has been covered with macrophag-specific ligands - O-stearyl amylopectin and maleylated bovine serum albumin [2].

The main disadvantages of this system are:

- $\quad$ susceptibility to phospholipid oxidation, and as consequence, lower stability;

- $\quad$ increased costs of the production technology;

- $\quad$ short half-life time in the body.

Many similar compositions developed by the leading specialists in the field are known [3-8].

The closest by composition known microparticulate systems are gelatin based microparticles covered with manosyl groups and loaded with isoniazid [9], and microspheres based on alginate-chitozan used for transport of different anti-tuberculosis drugs [10].

The main disadvantage of these systems is the fact that they only facilitate accumulation of drugs in the macrophages, but do not facilitate their penetration in the mycobacterial cell.

In the field of new anti-mycobacterial drugs, recently, many groups of researchers have proposed entities from different chemical classes: thiolactomycins [11], benzothiazones [12], substituted quinolinyl chalcones [13], cinnamic derivatives [14].

Development of new classes of anti-tuberculosis drugs is in permanent emergency since the resistance to older ones appears sooner than the new ones are registered. 


\section{Cyclodextrins and their role in anti-mycobacterial formulations}

Cyclodextrins are a family of cyclic natural oligosaccharides and their semi-synthetic derivatives. Naturally occurring $\alpha$-, $\beta$-, and $\gamma$-cyclodextrins are torus-like macro-rings built up from 6,7 , and 8 glucopyranose units, respectively (Table 1). As a consequence of ${ }^{4} \mathrm{C}_{1}$ conformation of the glucopyranose moieties, all the primary hydroxyl groups are situated on the one edge of the torus, while all the secondary ones are situated on the other. The internal cavity of the cyclodextrins is lined by the hydrogen atoms and the glycosidic oxygen bridges, which produce a high electron density, causing some hydrophobicity [15].

In an aqueous solution, the cyclodextrins' cavity is filled with water molecules that are energetically unfavored due to polar-non-polar interactions and, therefore, can be readily substituted by any less polar guest-molecule added to the solution.

The main reasons of cyclodextrins popularity as hosts for inclusion of different substances are:

- they are produced from a renewable natural material (starch) applying environmental-friendly technologies (enzymatic conversion);

- they are relatively cheap and are produced in amounts of thousands of tons per year;

- they are nontoxic in consumable concentrations and their secondary toxic effects can be easily eliminated by an appropriate chemical modification;

- $\quad$ they are biodegradable and do not pollute the environment [15].

Table 1

Properties of cyclodextrins [15].

\begin{tabular}{|c|c|c|c|}
\hline Parameters & $\alpha$-cyclodextrin & $\beta$-cyclodextrin & $\gamma$-cyclodextrin \\
\hline $\begin{array}{l}\text { Number of glucopyranose } \\
\text { fragments }\end{array}$ & 6 & 7 & 8 \\
\hline Molecular weight & 973 & 1135 & 1297 \\
\hline Internal cavity diameter $(\mathrm{nm})$ & $0.47-0.53$ & $0.60-0,66$ & $0.75-0.83$ \\
\hline $\begin{array}{l}\text { External diameter } \\
(\mathrm{nm})\end{array}$ & $1.46 \pm 0.04$ & $1.54 \pm 0.04$ & $1.75 \pm 0.04$ \\
\hline $\begin{array}{l}\text { Torus height } \\
(\mathrm{nm})\end{array}$ & $0.79 \pm 0.01$ & $0.79 \pm 0.01$ & $0.79 \pm 0.01$ \\
\hline Cavity volume approx. (mL/mol) & 104 & 157 & 256 \\
\hline$[\alpha]_{D}$ at $25^{\circ} \mathrm{C}$ & $150 \pm 0.5$ & $162.5 \pm 0.5$ & $177.4 \pm 0.5$ \\
\hline $\begin{array}{l}\text { Water solubility } \\
\left(\mathrm{g} / 100 \mathrm{~mL} \text { at } 25^{\circ} \mathrm{C}\right)\end{array}$ & 14.5 & 1.85 & 23.2 \\
\hline
\end{tabular}

Previously, a number of antimycobacterial formulations containing cyclodextrins have been proposed. Many of them contain complexes of an antimycobacterial drug with cyclodextrin with purpose to increase the solubility of the drug and reduce its toxicity. Thus complexes of rifampicin with sucralose and $\beta$-cyclodextrins have been proposed for pulmonary delivery $[16,17]$. The role of the cyclodextrins under this study was to enhance the solubility and permeation of poorly water soluble rifampicin through the biological membranes. As such, cyclodextrins act as permeation enhancers by carrying the drug through the aqueous barriers which exists before the lipophilic surface of biological membranes [16].

Similar complexes have been obtained for other antituberculosis agents: pirazinamide [18], isoniazid [19, 20].

Another formulation includes cyclodextrin nanoparticles/microparticles containing rifabutin is implied for oral, intravenous or intramuscular administration. According to the invention authors, the main role of cyclodextrins in this formulation is to enhance solubility of rifabutin [21].

Besides the use of cyclodextrins as pharmaceutical auxiliary agents, they have started to attract a lot of attention due to their intrinsic biological activity or physiological effects that are specific for their derivatives. Thus, carboxyl thio 
ether derivatives of $\gamma \mathrm{CD}$ are used as a new class of selective relaxant binding agents [22]. Some $\beta C D$ derivatives proved to inhibit anthrax lethal toxin by blocking the transmembrane pore formed by its protective antigen subunit [23, 24], others are effective in inhibition of $\alpha$-hemolysin playing important role in the pathogenesis of Staphilococcus aureus, a bacteria that causes severe forms of pneumonia [25]. Interestingly, cyclodextrins have also been proven to have lysis activity against certain strains of Bacillus, but not against other Gram-positive or Gram-negative bacteria [26].

The types of biological activity of cyclodextrins important for their use in medicine were classified in [27] as follows:

- $\quad$ effects based on the ability of cyclodextrins to form inclusion complexes with exogenous substances as guest molecules;

- $\quad$ effects based on the ability of cyclodextrins to form inclusion complexes with endogenous substances as guest molecules;

- $\quad$ effects based on the chemical nature of cyclodextrins and their derivatives;

- $\quad$ effects based on the ability of cyclodextrins to block endogenous and exogenous macromolecules.

All these types of activity have been analyzed by us as useful for antifungal formulations [28].

We have suggested that complexation of cholesterol by cyclodextrins can be used to increase the permeability of the mycobacterial cell wall for penetration by antimycobacterial compounds. Thus, we have proposed to obtain new nanoencapsulated in cyclodextrins antituberculosis remedies with higher efficiency and fewer side effects as compared to the existing drugs [29]. In the proposed formulation, cyclodextrins play the roles of solubilizing agents and promoters of the antimycobacterial substances penetration inside the mycobacterial cell. The nano-encapsulated drugs are then loaded into the alginate-chitosan microparticles that help them penetrate into macrophages infected with M. tuberculosis [30].

Preliminary results (unpublished) of the biological tests of antimycobacterial activity of the obtained substances and systems have demonstrated that antituberculosis efficiency of the studied substances changes in association with different cyclodextrins. Thus, $\beta$-cyclodextrin, one of the naturally occurring cyclodextrins, seems to enhance antituberculosis activity of the associated oxadiazole derivative, while sulfobutyl ether of $\beta$-cyclodextrin does not have this influence. This observation might be explained by the fact that sulfobutyl ether of $\beta$-cyclodextrin possesses certain level of charge of the molecule due to the presence of sulfobutyl ether groups, which makes it less suitable for cholesterol complexation than simple $\beta$-cyclodextrin. Namely cholesterol complexation is considered to be in the core of mechanism of cyclodextrins activity as promoters of antituberculosis compounds penetration through the mycobacterial cell wall (Figure 1).

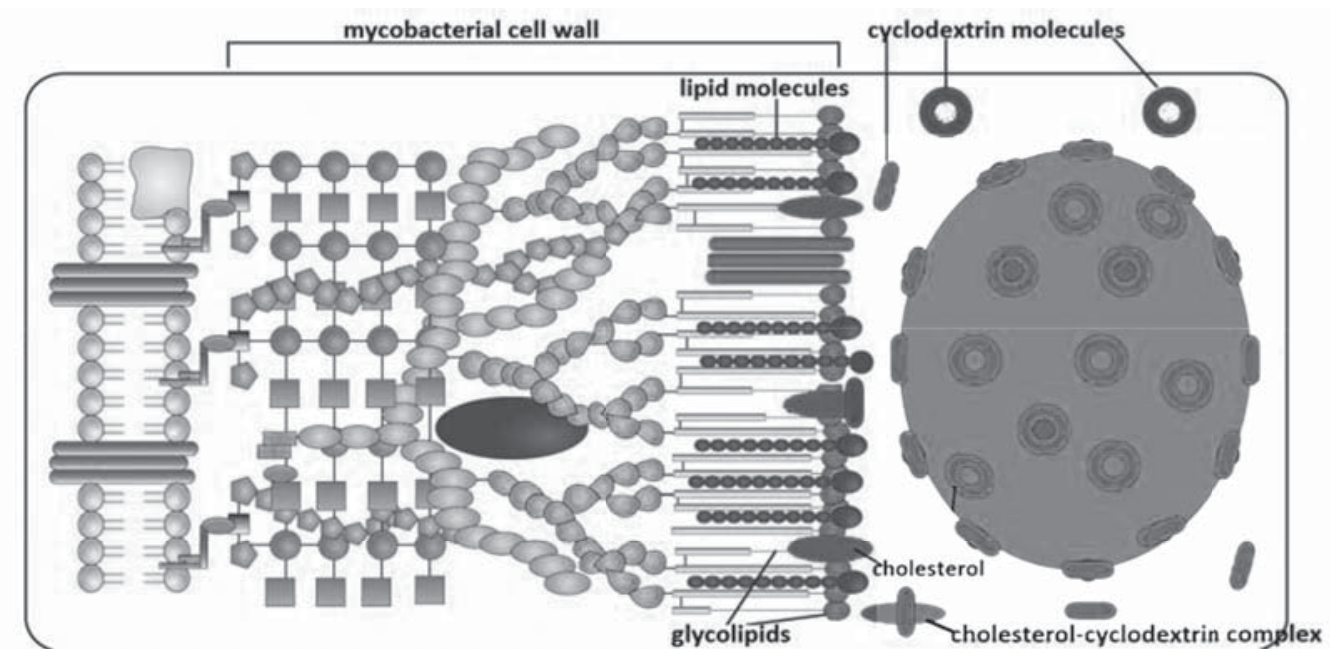

Figure 1. Extraction of cholesterol molecules from the mycobacterial cell wall.

It has been demonstrated before that in the case of Mycobacterium tuberculosis cyclodextrins extract cholesterol deposited in the mycobacterial cell wall [31] that leads to disorganization of the protective lipid bilayer and, thus, increases its permeability for drug molecules [32].

$\beta C D$ s are particularly efficient sterol acceptors, apparently because the size of their inner hydrophobic cavity matches the size of the sterol molecule (Figure 2). As a more potent cholesterol-extracting agent, a randomly methylated derivative of $\beta C D$ is usually used.

Thus, the studies performed by Castagne and collaborators [33] have shown that the high substituted dimethyl$\beta C D$ (D.S. 2.0) and randomly methylated $\beta C D$ (D.S. 1.8) are efficient cholesterol solubilizers or extractors from cell membranes. Molecular modeling studies performed by this group have also indicated that 1:1 complexes of cholesterol 
with these cyclodextrins are not favorable, while all four 1:2 conformations are possible. Trimethyl- $\beta$-cyclodextrin (D.S. 3.0) showed an unexpected behavior not being able to extract high amounts of cholesterol despite its good solubilizing properties. Moreover, only two of all the complexes conformations of this cyclodextrin with cholesterol gave favorable complexation energies, which could explain its difficulty to form complexes and to extract this sterol. Methylated derivative of $\beta C D$ with low degree of substitution (D.S. 0.5) proved to have the lowest affinity towards cholesterol and the lowest solubilizing properties towards it. However, molecular modeling studies revealed that CD complexes, both 1:2 and 1:1, with cholesterol had the highest interaction or complexation energies [33].
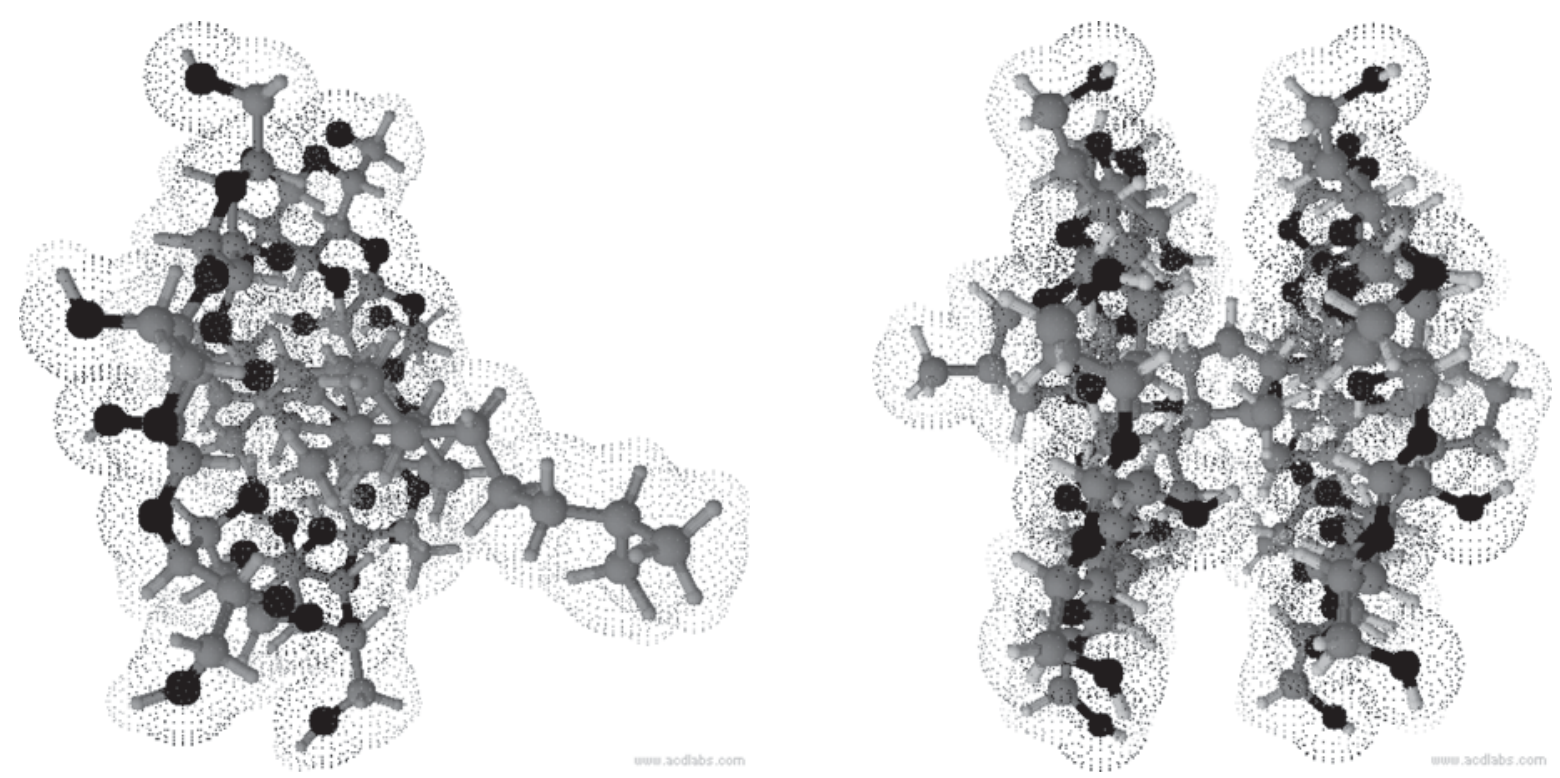

Figure 2. Schematic representation of 1:1 (left) and 1:2 (right) inclusion complexes of sterols with $\beta C D$.

\section{Conclusions}

Cholesterol complexation by cyclodextrins increases permeability of the mycobacterial cell wall and promotes penetration of antimycobacterial compounds inside. First results of the biological tests of antimycobacterial activity of the antimycobacterial compounds and their complexes with cyclodextrins have demonstrated that antituberculosis efficiency of the studied substances changes in association with different cyclodextrins. Thus, $\beta$-cyclodextrin, one of the naturally occurring cyclodextrins, seems to enhance antituberculosis activity of the associated oxadiazole derivative, while sulfobutyl ether of $\beta$-cyclodextrin does not have this influence. This observation might be explained by the fact that sulfobutyl ether of $\beta$-cyclodextrin possesses certain level of charge of the molecule due to the presence of sulfobutyl ether groups, which makes it less suitable for cholesterol complexation than unsubstituted $\beta$-cyclodextrin.

\section{Acknowledgments}

The authors are grateful for the funding of this research under the Moldovan State Program project 14.518.04.08A.

\section{References}

1. Zignol, M.; van Gemert, W.; Falzon, D.; Sismanidis, C.; Glaziou, P.; Floyd, K.; Raviglione, M. Surveillance of anti-tuberculosis drug resistance in the world: an updated analysis, 2007-2010. Bulletin of the World Health Organization, 2012, 90, pp. 111D-119D.

2. Vyas, S. P.; Kannan, M. E.; Jain, S. et al. Design of liposomal aerosol for improved delivery of rifampicin to alveolar macrophages. International Journal of Pharmaceutics, 2004, 269, pp. 37-49.

3. Pandey, R.; Sharma, S.; Khuller, G. K. Nebulization of liposome encapsulated antitubercular drugs in guinea pigs. International Journal of Antimicrobial Agents, 2004, 24, pp. 93-94.

4. Sharma, R.; Saxena, D.; Dwivedi, A. K. et al. Inhalable microparticles containing drug combinations to target alveolar macrophages for treatment of pulmonary tuberculosis. Pharmaceutical Research, 2001, 18, pp. 1405-1410. 
5. Edwards, D.; Fiegel, J.; Sung J. Particles for treatment of pulmonary infection. USA Patent, 2007, No. 2007011396.

6. Shim, C. K.; Yang R. Pharmaceutical composition for lung targeting. Korea Patent, 2008, No. 20080043333.

7. Ahmad, Z.; Pandey, R.; Sharma, S.; Khuller, G.K. Alginate nanoparticles as antituberculosis drug carriers: formulation development, pharmacokintecs and therapeutic potential. The Indian Journal of Chest Diseases\&Allied Sciences, 2006, 48, pp. 171-176.

8. Tiwari, S.; Chaturvedi, A.P.; Tripathi, Y.B.; Mishra, B. Macrophage-specific targeting of isoniazid through mannosylated gelatin microspheres. AAPS PharmSciTech, 2011, 12(3), pp. 900-908.

9. Saraogi, G.K.; Sharma, B.; Joshi, B.; Gupta, P.; Gupta, U.D.; Jain, N.K.; Agrawal, G.P. Mannosylated gelatin nanoparticles bearing isoniazid for effective management of tuberculosis. Journal of Drug Targeting, 2011, 19(3), pp. 219-227.

10. Pandey, R.; Khuller, G.K. Chemotherapeutic potential of alginate-chitosan microspheres as antitubercular drug carriers. Journal of Antimicrobial Chemotherapy, 2004, 53, pp. 635-640.

11. Kamal, A.; Azeeza, S.; Malik, M.S. et al. Efforts towards the development of new antitubercular agents: potential for thiolactomycin based compounds. Journal of Pharmacy and Pharmaceutical Sciences, 2008, 11, pp. 56(s)-80(s).

12. Makarov, V.; Manina, J.; Mikusova, K. et al. Benzothiazinones kill Mycobacterium tuberculosis by blocking arabinan synthesis. Science, 2009, 5928, pp. 801-804.

13. Sharma, M.; Chaturvedi, V.; Manju, Y.K. et al. Substituted quinolinyl chalcones and quinolinyl pyrimidines as a new class of anti-infective agents. European Journal of Medicinal Chemistry, 2009, 44, pp. 2081-2091.

14. De, P.; Yoya, G.K.; Bedos-Belval, F.; Constant, P. et al. Design, synthesis and biological evaluation of new cinnamic derivatives as antituberculosis agents. Journal of Medicinal Chemistry, 2011, 54, pp. 1449-1461.

15. Szejtli, J. Past, present, and future of cyclodextrin research. Pure and Applied Chemistry, 2004, 76(10), pp. 1825-1845.

16. Patil, J.S.; Suresh, S. Physicochemical characterization, in vitro release and permeation studies of respirable rifampicin-cyclodextrin inclusion complexes. Indian Journal of Pharmaceutical Science, 2009, 71, pp. 638-643.

17. Nanduri, B.; Neelam S. K.; Kakulapati R.R.; Jhillu S.Y. Inclusion complex of anti-tubercular rifampicin with beta-cyclodextrin or 2-hydroxypropyl beta-cyclodextrin and a process for producing the same. International Patent, 2004, No. 2004041284.

18. Aree, T.; Chaichit, N. Inclusion complexes of $\beta$-cyclodextrin with pyrazinamide and piperazine: Crystallographic and theoretical studies. Supramolecular Chemistry, 2009, 21(5), pp. 384-393.

19. Terekhova, I. V.; Kumeev, R. S. Thermodynamics of inclusion complexes between cyclodextrins and isoniazid. Russian Journal of Physical Chemistry A, 2010, 84(1), pp. 1-6.

20. Teixeira, M. G.; De Assis, J. V.; Soares, C. G.; Venâncio, M. F.; Lopes, J. F.; Nascimento Jr, C. S.; De Almeida, W. B. Theoretical and Experimental Study of Inclusion Complexes Formed by Isoniazid and Modified $\beta$-Cyclodextrins: 1H NMR Structural Determination and Antibacterial Activity Evaluation. The Journal of Physical Chemistry B, 2014, 118(1), pp. 81-93.

21. Geliperina, S.E.; Maxiemnko, O.O.; Vanchugova, L.V.; Shipulo, E.V.; Babii, V.E.; Ignatiev, A.V. Pharmaceutical composition based on cyclodextrin nanoparticles containing rifabutin, method for its obtaining, method for treatment of mycobacteriosis and helicobacter infection. Euroasian Patent, 2010, No. 2010016410 (In Russian).

22. Welliver, M.; McDonough, J.; Kalynych, N.; Redfern, R. Discovery, development, and clinical application of sugammadex sodium, a selective relaxant binding agent. Drug Design, Development and Therapy, 2008, 2, pp. 49-59.

23. Karginov, V.A.; Nestorovich, E.M.; Yohannes, A.; Robinson, T.M.; Fahmi, N. E.; Schmidtmann, F.; Hecht, S.M.; Bezrukov, S.M. Search for cyclodextrin-based inhibitors of anthrax toxins: synthesis, structural features, and relative activities. Antimicrobial Agents and Chemotherapy, 2006, 50(11), pp. 3740-3753. 
24. Joshi, A.; Kate, S.; Poon, V.; Mondal, D.; Boggara, M.B.; Saraph, A.; Martin, J.T.; McAlpine, R.; Day, R., Garcia, A.E.; Mogridge, J.; Kane, R.S. Structure-based design of a heptavalent anthrax toxin inhibitor. Biomacromolecules, 2011, 12(3), pp. 791-796.

25. Ragle, B.E.; Karginov, V.A.; Wardenburg, J.B. Prevention and treatment of Staphylococcus aureus pneumonia with a $\beta$-cyclodextrin derivative. Antimicrobial Agents and Chemotherapy, 2010, 54(1), pp. 298-304.

26. Zhang, H.M.; Li, Z.; Uematsu, K.; Kobayashi, T.; Horikoshi, K. Antibacterial activity of cyclodextrins against Bacillus strains. Archives of Microbiology, 2008, 190(5), pp. 605-609.

27. Duca, G.; Ivancic, A.; Boldescu, V. Cyclodextrins - fields of application. Part II. Chemistry Journal of Moldova, 2012, 7(2), pp. 39-45.

28. Macaev, F.; Boldescu, V.; Geronikaki, A.; Sucman, N. Recent advances in the use of cyclodextrins in antifungal formulations. Current Topics of Medicinal Chemistry. 2013, 21, pp. 2677-2683.

29. Boldescu, V.; Bratu, I.; Borodi, Gh.; Kacso, I.; Duca, Gh.; Macaev, F.; Pogrebnoi, S.; Ribkovskaia, Z. Study of binary systems of beta-cyclodextrin with a highly potential anti-mycobacterial drug candidate. Journal of Inclusion Phenomena and Macrocyclic Chemistry, 2012, 74, pp. 129-135.

30. Boldescu, V. Nanoparticles and microparticles in tuberculosis treatment. Akademos, 2013, 1(28), pp. 108-111 (In Romanian).

31. Brzostek, A.; Pawelczyk, J.; Rumijowska-Galewicz, A.; Dziadek, B.; Dziadek, J. Mycobacterium tuberculosis is able to accumulate and utilize chiolesterol. Journal of Bacteriology, 2009, 191(21), pp. $6584-6591$.

32. Donova, M.N.; Nikolayeva, V.M.; Dovbnya, D.V. et al. Methyl- $\beta$-cyclodextrin alters growth, activity and cell envelope features of sterol-transforming Mycobacteria. Microbiology, 2007, 153, pp. 1981-1992.

33. Castagne, D.; Dive, G.; Evrard, B.; Frédérich, M.; Piel, G. Spectroscopic studies and molecular modeling for understanding the interactions between cholesterol and cyclodextrins. Journal of Pharmacy and Pharmaceutical Sciences, 2010, 13(2), pp. 362-377. 